\title{
Supporting Empathy Through Embodiment in the Design of Interactive Systems
}

\author{
Abstract \\ Whilst empathy is considered an essential component \\ of what it means to be human, it is arguably absent as \\ a design objective when creating modern \\ communication systems. This paper presents an \\ approach to designing for, as opposed to with, empathy \\ using the example of two design interventions to create \\ embodied rituals reflecting prayers and worries of \\ individuals within a church community. The aim of \\ these interventions is to facilitate conversation and \\ support within the community, thus generating \\ empathy between community members, and inciting \\ prosocial behaviour through embodied cognition.
}

\section{Author Keywords}

Empathy; Design; Digital Empathy; Embodied Actions

\section{ACM Classification Keywords}

H.5.m. Miscellaneous

\section{General Terms}

Design, Human Factors. 


\section{Introduction}

Empathy

Empathy defines our ability to understand and share the feelings of another [1]. It is an emotional capacity that has arguably been overlooked within the design of digital systems [2]. This is problematic, as empathy may be viewed as one of the essential components of the 'human condition', with observation of atypical empathetic responses suggested as indicators of a number of autism spectrum and personality disorders that inhibit an individual's ability to relate to others. If empathy is indeed such an important facet of humanity we argue that it should be considered in the design of the ever-increasing number of digital communication systems. In the absence of a full understanding of how designers might address this goal, there is a clear need for research that specifically addresses the notion of designing for empathy [2].

Whilst there is a rich and varied literature relating to empathy, how it is experienced, whether and how it may be taught, its effect upon attitudes and behaviour, and its application to a wide variety of applied fields of study [3], it has yet to be completely understood. It is probable that the lack of discussion relating to the incorporation of empathy within digital design is caused by the notion that it, along with other emotions, is extremely difficult [3], or even impossible $[4,5]$ to sense automatically with a computer. The approach taken here, however, is not to attempt to sense empathy, but merely to design systems in such a way as to afford empathetic feelings and behaviour within a community.

The positive effects of empathy go far beyond improving attitudes and motivating prosocial behaviour (voluntary behaviour intended to benefit others) [3] Indeed, it has been found that inducing empathy towards animals and plants can increase pro-

environmental behaviour [6]. It follows, therefore, that designing for the promotion of empathy within a

community could increase pro-community and prosocial behaviour: improving the coherence and 'spirit' of the community, and thus potentially increasing the happiness and wellbeing of its members.

It should be noted that the concept of designing for empathy is completely distinguished from the similarly named field of 'Empathic Design', which is concerned more with designing with empathy for a particular user group. There is, in fact, very little in the current design literature relating to the creation of systems for facilitating or encouraging empathetic behaviour between subjects [2].

Rituals and Embodiment

There is a significant strand of the psychological literature that attests to the potency of physical acts and 'rituals', demonstrating the notable and sometimes surprising effects that behaviour can have on the human psyche. The link between mind and body has been explored most profitably in an area that has become known popularly as 'embodied cognition': the concept that certain states of the body modify states of the mind [7]. There are a range of studies that illustrate the positive psychological effects of carrying out particular actions, such as [8] and [9], which reported that participants who physically washed their hands after recalling an unethical deed experienced significantly reduced negative moral emotions (i.e., shame, guilt etc.). 
In a separate line of research, [10] asked participants to write their likes and dislikes relating to their physical bodies on a piece of paper. The researchers found that those individuals who then tore up and discarded this paper relied less upon those thoughts in forming subsequent judgements than those who kept them, and that this effect was enhanced if the retained paper was kept in a safe place (i.e., in a participant's pocket). The effects of such ritualistic actions on our thoughts, feelings and behaviours do not even need to have a logical or causal connection in order to be influential. A series of experiments by [11] illustrated that engaging in novel physical rituals (designed and assigned by an experimenter) reduced the grief reported after recalling a series of loss events.

The above experiments illustrate the effect of physical action on regulating emotional states. In another experiment in [10], the authors found evidence that the effects were stronger when a physical action was performed rather than simply imagined, and [9] reported that physically undertaking an act (washing hands) was more effective than simply watching the act on a video. This therefore suggests that facilitating the

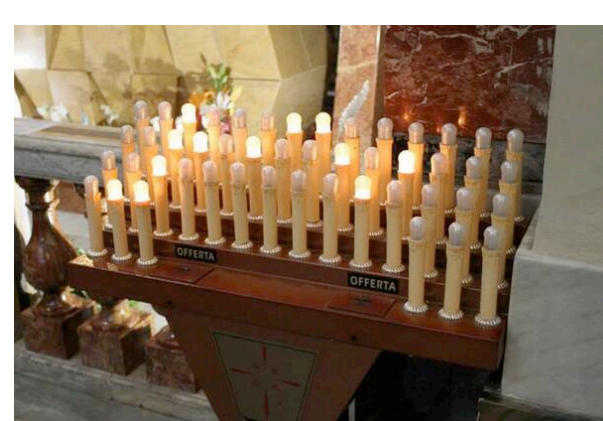

Figure 1. Electrified votive candles in Sicily. (physical) expression of such empathetic concern has the potential to have positive psychological benefits for all those involved.

\section{Designing for Empathy}

This work has taken place in collaboration with an existing cohesive community: the congregation of St Peter De Beauvoir Town Anglican Church in Hackney, London. A church community was chosen as they already have a number of embodied rituals in place, intended to facilitate members in sharing their prayers and worries in a personal way with God. It is these personal rituals (and their associated artefacts) that will be digitally augmented in order to enable these personal thoughts and feelings to be shared with their community (if they so wish) in the expectation that this will afford the development of empathy. The design of these augmentations has taken place following extensive discussion with the Vicar relating to the usage and potential of each ritual. The pre-existing artefacts associated with the rituals will remain in the church alongside the new augmented versions, so that members of the congregation only have to utilise the augmented systems if they so wish.

\section{Digital Votive Candles}

The first system designed for the project relates to the lighting of votive candles ${ }^{1}$ as a physical ritual symbolising a prayer intention, often relating to a specific person or outcome. This is an act common within many branches of Christianity as well as Hinduism, Buddhism and other religious groups. At St Peter De Beauvoir Town, votive candles are lit within the church itself, and the associated prayer intentions are held privately to the individual. It is thought that this symbolic physical act of lighting a candle reinforces the positive benefits associated with a prayer.

The objective for the augmentation of the votive candles is to maintain the embodied ritual of lighting a candle, but allow the associated prayer intention to be

${ }^{1}$ Votive candles are lit in a church, normally (in a Christian Church) before a statue or image of Jesus Christ; Mary, Mother of Christ; or another Saint. The candle is a symbol of a 'prayer intention' - the purpose for which you will pray, and follows the common Christian symbolism of light representing God. 


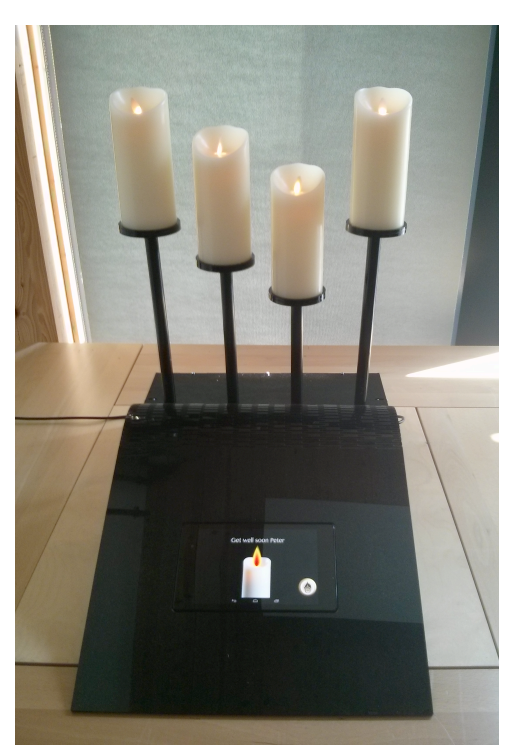

Figure 2. The '4Candles' digital votive candles. shared with the rest of the community, in the hope that this will create greater empathy within the community. A physical artefact will therefore be introduced into the church that will fulfil this function. There is already evidence of both the electrification and digitisation of votive candles (e.g. Figure 1 and [12] respectively), but thus far there have been no attempts to extend the impact of these symbolic acts within a community, either through the increased functionality of systems, by the facilitation of communication.

The '4Candles' digital votive candles artefact comprises a physical candelabra (containing four digitally enhanced wax candles) with a built-in touch screen interface, as is illustrated in Figure 2 . The touch screen runs an application (Figure 3 ) that can be used by participants to light a candle with their own prayer intention. When idle, the application cycles a display of the previous prayer intentions associated with the candles, along with an animated flickering candle that is intended to draw the attention of passing members of the community.

The prayer on screen changes every 30 seconds, and with each change one of the digital candles is extinguished and re-lit in order to symbolise the original lighting of the candle for that particular prayer intention. In this way, all of the logged prayers will be regularly displayed within the church for their

requested period of time, and thus shared with any other members of the church community that are present. Before display, each message requires approval by the Vicar via a simple web interface. In this way, abuse of the system can be avoided, and any inappropriate or offensive messages can be prevented

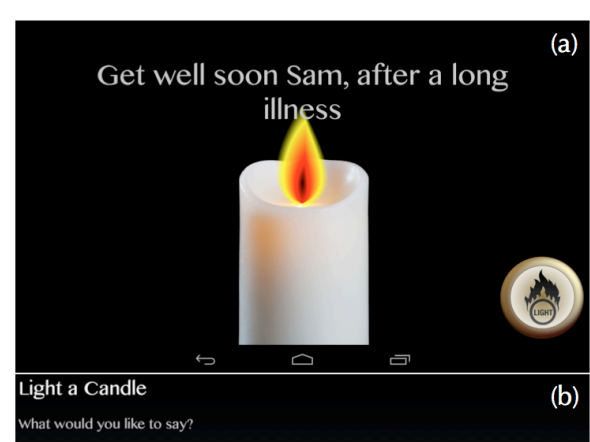

from being displayed upon the screen in the church, which is a highly sensitive location.

The act of extinguishing and relighting a candle each time a new prayer intention is displayed also furthers the impression that the system is 'active', as well as reinforcing the notion that a prayer intention belongs to a particular candle, as

Android Screenshots

would be the case with a traditional votive candle. Crucially though, the physical extinguishing of the candles contributes to the physicality of the ritual of lighting a candle, which is intended to further the effect of embodied cognition within the act of lighting the a candle, promoting the benefits of embodied cognition to the user, as well as helping to ensure that the augmented version is viewed as being comparable in experience to lighting a candle in the traditional manner.

\section{Digital Font}

The second system designed to facilitate empathy within the church is that of the font, which is currently used for members of the congregation (normally children) to 'let go' of their fears and worries by the 


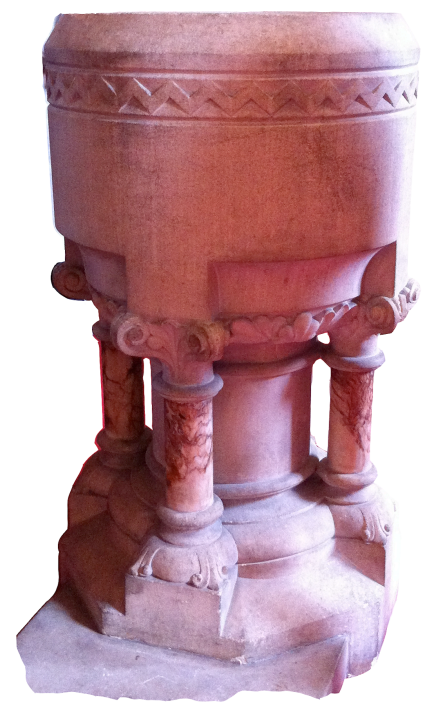

Figure 4. The stone baptismal font at St Peter De Beauvoir Town Church, Hackney, London. ritual of placing a pebble (representing the worry) into the water and physically letting go of it. Whilst not as commonplace as the votive candles, and indeed not the traditional function of the (baptismal) font in a church ${ }^{2}$, this ritual represents a very effective literal representation of 'letting go' of one's worries, and as such will benefit from the positive effects of embodied cognition. As with the prayer intentions associated with the votive candles, however, these worries are currently kept privately to the individual. They are not shared either with the Vicar or other members of the community as part of this ritual, and as such do not promote communication within the community, or any of the benefits that may arise from this.

Once again, the objective of the digital font is therefore to increase engagement with the ritual and facilitate communication within the community, this time of their collective worries, in order to further develop understanding and hopefully empathy between community members. As the current font ritual already represents a classic example of embodied cognition, a non-invasive digital augmentation of the existing font within the church (Figure 4) was used, as opposed to the introduction of a new artefact.

The "Font of Solace" digital font is based around a tablet computer running a custom application that allows the user to 'write' their worry onto the screen using the provided stylus, before 'sending' this worry to

2 A baptismal font is normally used as part of the Christian sacrament of Baptism (also known as Christening by some Christian denominations), whereby holy water from the font is symbolically poured over the head of the subject (normally a child), as part of their initiation into the church. the font. When the users then physically touch the water (detected with a Microsoft Kinect), the words that they wrote appear in the water (via an overhead projector) before drifting away into the virtual 'ether'. As with the candles, this hand-written message is also logged to a central server, and requires approval from the Vicar before appearing on a display screen within the church. This display will once again cycle through all of the most recent worries that people have logged, so that they may be shared with the rest of the community, for the purpose of generating empathy.

The use of hand-written text disappearing into the 'ether' is intended to reinforce the embodiment of the ritual, with the disappearing worry represented in the user's own handwriting making the ritual more 'personal' than it would in an anonymous typeface. Maintaining the requirement for the user to physically touch the water retains the effective physical metaphor of 'letting go' of the worry, as opposed to simply pressing a button, or interacting with a screen.

\section{Conclusion}

Whilst very much a 'work in progress' this research is intended to stimulate debate around designing for empathy, particularly in a community setting. Two systems have been presented that are designed to allow a congregation to communicate their prayers and worries not only to God, as is currently the case, but also to other members of the community through existing ritual acts. It is intended that these rituals will have a positive effect upon the psyche of users through embodied cognition; and that this communication will enable the community to be more aware of its own members, develop a greater understanding of each other, and afford the development of mutual empathy. 
Our approach centred upon the use of an existing cohesive community, and upon the principle of extending the functionality of existing symbolic rituals and their associated artefacts within the church setting. This approach has minimised the required level motivation for community members to use these artefacts, which facilitate rituals with which they are already familiar and may even routinely enact already. Similarly, the selection of a pre-existing community is intended to facilitate conversation, as community members would be expected to feel more able to talk to each other than may be the case with a group of strangers.

Future work on this project will comprise an evaluation of the experience of these systems by members of the church, and the extent to which they were able to afford the development of empathy within the community.

\section{Acknowledgements}

The authors would like to thank Julia Porter-Pryce, Vicar of St Peter De Beauvoir Town, for her support and enthusiasm for this project and the EPSRC through grant EP/L003635/1.

\section{References}

[1] Oxford Dictionaries:

http://www.oxforddictionaries.com/definition/englis h/empathy. Last accessed 04/08/2014.

[2] Coulton, P., Huck, J., Hudson-Smith, A., Ralph, B., Mavros, P., Roberts, J., \& Powell, P. (2014). Designing interactive systems to encourage empathy between users. In DIS Companion '14 Proceedings of the 2014 companion publication on Designing interactive systems. (pp. 13-16). New York: ACM. 10.1145/2598784.2602770
[3] Belman, J., \& Flanagan, M. (2009). Designing Games to Foster Empathy. International Journal of Cognitive Technology, 14(2), 11.

[4] Gaver, W. (2009). Designing for emotion (among other things). Philosophical Transactions of the Royal Society B: Biological Sciences, 364(1535), 3597-3604.

[5] Boehner, K., DePaula, R., Dourish, P., \& Sengers, P. (2005, August). Affect: from information to interaction. In Proceedings of the 4th decennial conference on Critical computing: between sense and sensibility (pp. 59-68). ACM.

[6] Berenguer, J. (2007). The effect of empathy in proenvironmental attitudes and behaviors. Environment and Behavior, 39(2), 269-283.

[7] Wilson, A. D., \& Golonka, S. (2011). Embodied cognition is not what you think it is. Front Psychol, 4: 58

[8] Zhong, C-B., \& Liljenquist, K. (2006). Washing away your sins: Threatened morality and physical cleansing. Science, 313, 1451-1452.

[9] Xu, H., Begue, L., \& Bushman, B. J. (2014). Washing the guilt away: effects of personal versus vicarious cleansing on guilty feelings and prosocial behaviour. Front Hum Neurosci, 8: 97.

[10] Brinol, P., Gasco, M., Petty, R. E., \& Horcajo, J. (2013). Treating thoughts as material objects can increase or decrease their impact on evaluation. Psychological Science, 24, 41-47.

[11] Norton, M. I., \& Gino, F. (2014). Rituals alleviate grieving for loved ones, lovers, and lotteries. Journal of Experimental Psychology: General, 143, 266-272.

[12] Light a Candle: http://www.gratefulness.org/candles. Last accessed 04/08/2014. 